\title{
The late 1970s bubble in Dutch collectible postage stamps
}

\author{
Philip Hans Franses ${ }^{1}$. Wouter Knecht ${ }^{1}$
}

Received: 18 July 2014 / Accepted: 4 April 2015 / Published online: 30 July 2015

(C) The Author(s) 2015. This article is published with open access at Springerlink.com

\begin{abstract}
Collectible postage stamp prices in the Netherlands witnessed a bubble in the late 1970s, while prices rapidly floored in the mid-1980s. We analyze 500 individual stamps prices (instead of a single index) to examine whether the bubble could somehow have been predicted and whether there were early warning signals. Also, we study whether the characteristics of these stamps mediated the bubble and the price landing afterward. Scarcity and initial price levels appear to have predictive value in various dimensions. Implications for recognizing bubbles in other asset prices are discussed.
\end{abstract}

Keywords Price bubbles · Philately $\cdot$ Postage stamps $\cdot$ Forecasting · Positive feedback

\section{JEL Classification $\quad \mathrm{G} 11 \cdot \mathrm{G} 12 \cdot \mathrm{Z} 11$}

\section{Introduction}

Speculative price bubbles seem to occur with regular frequencies in various economic markets. Such markets can concern financial markets and housing markets, but also other assets like modern art, tulips, metals and internet-associated products can experience speculative bubbles, see Galbraith (1993), Garber (1990), Froot and Obstfeld

We thank Erik Kole, Chris Veld, Patrick Verwijmeren, an associate editor and two anonymous referees for helpful comments. The data in this paper can be obtained upon request.

$\triangle$ Philip Hans Franses

franses@ese.eur.nl

1 Econometric Institute, Erasmus School of Economics, PO Box 1738, 3000 DR Rotterdam, The Netherlands 
(1991) and Smith et al. (1988), to mention just a few of the many relevant references. It seems common consensus to assume that speculative bubbles sometime emerge and that in many situations there is not much to do against it. The prevention of price bubbles is believed to be difficult if not even impossible. At the same time, it does seem possible to design methods to diagnose if a price bubble is currently happening, and also early warning signaling methods can be designed, see West (1987) for an early method and Homm and Breitung (2012) for a recent evaluation of various testing methods. In the present study, we also analyze various characteristics of a speculative bubble, where our market of interest concerns collectible stamps in the Netherlands.

In a recent study, Dimson and Spaenjers (2011) document the investment performance of collectible stamps, in their case British postage stamps. Amongst other things, these authors show that, ex post, stamps seem to hedge against unexpected inflation and that their long-run returns may sometimes outperform those of various financial assets. Veld and Veld-Merkoulova (2007) demonstrated for British stamps that "adding stamps to stock portfolios can improve the investment performance of investors." At the same time, Dimson and Spaenjers (2011) show that prices of collectible stamps have features that mimic those of financial assets. Taking this result somewhat further, collectible stamp prices may then also sometimes suffer from speculative bubbles, and it is this notion that is pursued in more detail in our present paper. Using a unique database, specifically compiled for this study, we analyze price patterns of 500 individual stamps for a period of 30 years, and we aim to indicate that much can be learned from these individual patterns, also in terms of signaling speculative price bubbles.

Due to a lack of systematically compiled data, only anecdotal evidence ${ }^{1}$ indicated that somewhere in the late 1970s there would have been a price bubble in Netherlands postage stamp prices. Our data analysis below will confirm this. Additional to price levels, we collect various properties of the individual stamps, like quantities issued and various qualities like series lengths and topical issues, and we use these properties to see whether they mediate the speculative bubbles. Indeed, one would, for example, expect that the prices of scarce stamps take off earlier than more common stamps and also that for these scarce stamps the price levels at the peak are higher. If such results would be obtained, then this could suggest novel ways to signal or even forecast future speculative bubbles for similar assets, like modern art prints (Pesando 1993).

Our basically data-driven empirical paper proceeds as follows. In the next section, we outline the data collection and we present various statistical properties of the data. Amongst other things, we demonstrate that price bubbles seem heterogeneous across the 500 stamps, which provides some argument against using general indexes in favor of analyzing disaggregated data. Next, we present a range of regression models, which should elicit how the individual properties of the stamps mediate with the price bubbles. In the concluding section, we summarize the main findings and we discuss implications for analyzing prices in other markets.

\footnotetext{
${ }^{1}$ See http://www.leopardi.nl/frm/visie.php, which is the Web site of one of the large Dutch stamp auctions (Leopardi).
} 


\section{Data}

Since long time and each year, the Dutch Stamp Dealers' Association (with Dutch abbreviation NVPH) publishes a price catalogue with the prices of all Dutch stamps and their varieties. We will use the mint prices. We managed to acquire past issues from individual collectors via various auction Web sites, which resulted in the collection of the catalogues of 1971 to and including 1999. We did not extend the sample beyond that period, as a speculative bubble was already observed for this sample. In contrast to studies like Cardell et al. (1995), we do not use auction prices but the (recommended) prices in the catalogues, as this allows us to study all stamps that were issued in a particular period.

Given that we only have the catalogues starting from 1971 onward, we consider post-WW2 stamps issued until 1970. Given that pre-WW2 stamps are often rare, but also can have various versions (in terms of misprints and special versions), we decided to start looking at stamps issued in 1945 and in later years. We thus consider the stamps with numbers NVPH 428-937, which were issued from 1945 to $1970^{2}$. We index the prices at $1971=1$. The price level in 1971 was in Dutch guilders, and we used the relevant inflation data (source: Statistics Netherlands) to create real price levels (indexes). In total, we consider 500 stamps, which associate with the indicated NVPH numbers, where we took account of some renumbering (the numbers 821-826 and 864-867 ceased to be included in catalogues after 1973). For most stamps, we can collect various features like quantity issued, although for 33 of the 500 stamps information on those quantities is missing. Hence, we sometimes analyze 500 data on stamps, whereas in some regression models we are thus restricted to 467 data points.

We first analyze some average characteristics of the 500 stamps, and later on we will zoom in on stamp-specific characteristics. When we set all prices equal to 1 for 1971, we can create 500 indexes (corrected for inflation), that is, we divide the yearly prices by the price quoted in 1971 . We start with an analysis of the average price index, which is depicted in Fig. 1. From Fig. 1, we observe an explosive growth in the period from 1971 to 1978 , then a constant level peak period from 1978 to around 1982 and then a decline toward a rather constant level from 1987 onward to 1999. A price bubble can be associated with the explosive growth in the beginning of the sample, that is, real prices on average increased from 1 to 2.3 , a return of $230 \%$ in just 5-6 years. The average inflation-corrected return over the full sample is close to $50 \%$, which is about $1.5 \%$ per year, a number that matches with the results in Dimson and Spaenjers (2011).

An application of the formal test for explosive behavior (Phillips et al. 2011) is based on the regression $y_{t}-y_{t-1}=\mu+\rho y_{t-1}+\alpha\left(y_{t-1}-y_{t-2}\right)+\varepsilon_{t}$, which we run for the samples 1973-1999, 1973-1998 until 1973-1976. The maximum value of the

\footnotetext{
2 We analyze mint prices of Dutch postage stamps as they are reported in the catalogues. As a reviewer rightfully points out: "some of these catalogue prices are the minimum price that the catalogue states whereas this minimum price is not really an indication of the value of the stamp, but rather represents a handling fee for the dealer to sell the stamp." Unfortunately, we have no data on actual prices with the dealers and with auctions. We are not aware of such data for our sample considered. There may be something like that for rare and pre-WW2 stamps, but in our case we have to deal with the prices as mentioned in the catalogues.
} 


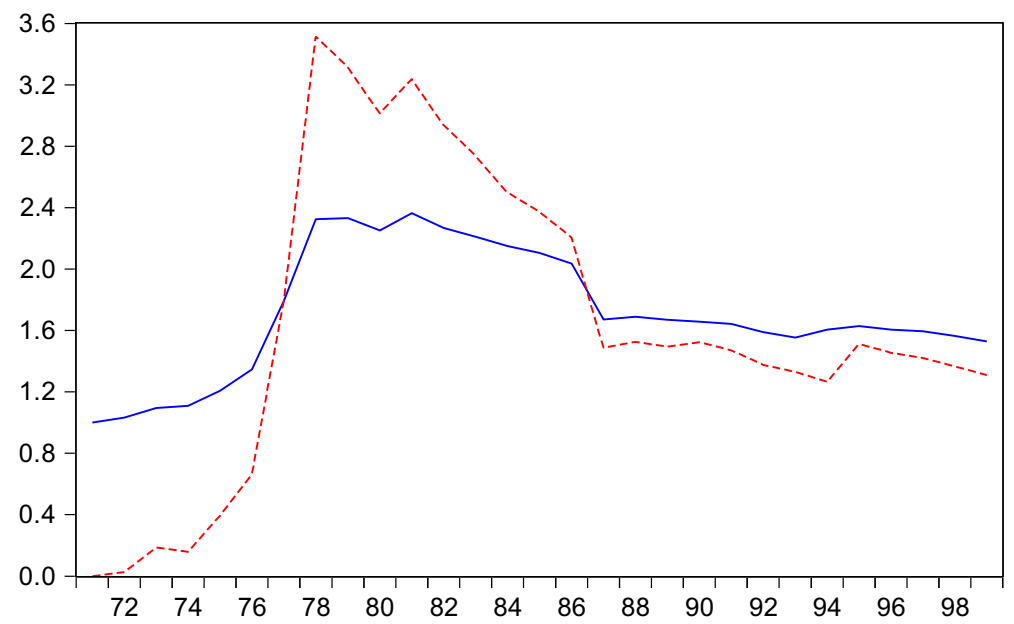

Fig. 1 Average of the index values (across 500 stamps), after correction for inflation, 1971-1999 (straight line), and the variance (per year) across the 500 index values, after correction for inflation, 1971-1999 (dotted line)

estimated $\rho$ is equal to 1.861 attained for the sample 1973-1978, with an associated $t$ value of 2.504. This $t$ value is also the maximum $t$ value across all samples. Comparing this value with the critical values as they are displayed in table 1 in Phillips et al. (2011) shows that there is evidence of explosive behavior at the $1 \%$ significance level. This suggests a bubble period lasting until and including 1978.

The variance across the 500 price indexes per year is also presented in Fig. 1. We observe that the time-series pattern of the variance of the price indexes is very similar to the pattern of the average values. Hence, when prices increase rapidly, this does not seem to occur for all stamps in a similar way. This suggests that there are characteristics of the individual stamps that associate with average and variance levels in a different way. It may be that more scarce stamps witness more rapid price increases than stamps that were issued with larger quantities.

Figure 1 shows that the average values and the variance are strongly related (the correlation equals 0.98). This suggests that individual properties of stamps mediate price changes and hence that a more detailed analysis can be insightful. As the $R^{2}$ is not a good indicator for correlation in case the data have a trend or non-stationary properties, we also consider an error correction model with one lag for the bivariate time series (average, variance). The (unreported) error correction terms are significant and the $R^{2}$ values are now around 0.96 for the bivariate model in growth rates. This again supports the close link between the two series in Fig. 1.

Before we turn to the heterogeneity, we first zoom in on the price bubble period to see whether there are any features of the data that elicit properties of that bubble. It is well appreciated that price bubbles are associated with so-called positive feedback, see Franses (2015). Usually, stationary time-series data show negative feedback, that is, there is a tendency to return to the mean. Explosive non-stationary processes have positive feedback (which can also be observed from the positive $\rho$ parameter in the 
Table 1 Percentage of stamps (per year) with positive changes in price and with positive differences in changes

\begin{tabular}{|c|c|c|}
\hline Year & $P(t)-P(t-1)>0$ & $\begin{array}{l}P(t)-2 P(t-1) \\
+P(t-2)>0\end{array}$ \\
\hline 1972 & 46.8 & NA \\
\hline 1973 & 51.0 & 64.2 \\
\hline 1974 & 45.4 & 29.0 \\
\hline 1975 & 49.8 & 72.6 \\
\hline 1976 & 58.4 & 72.8 \\
\hline 1977 & 76.2 & 91.4 \\
\hline 1978 & 68.6 & 70.8 \\
\hline 1979 & 39.0 & 36.0 \\
\hline 1980 & 17.8 & 9.8 \\
\hline 1981 & 58.0 & 92.0 \\
\hline 1982 & 12.6 & 38.2 \\
\hline 1983 & 4.0 & 85.2 \\
\hline 1984 & 10.2 & 8.6 \\
\hline 1985 & 8.2 & 89.4 \\
\hline 1986 & 0.4 & 75.6 \\
\hline 1987 & 34.6 & 38.4 \\
\hline 1988 & 8.6 & 68.6 \\
\hline 1989 & 0.0 & 0.2 \\
\hline 1990 & 12.0 & 12.2 \\
\hline 1991 & 14.0 & 12.8 \\
\hline 1992 & 4.8 & 83.4 \\
\hline 1993 & 5.0 & 89.0 \\
\hline 1994 & 27.0 & 31.4 \\
\hline 1995 & 7.4 & 71.2 \\
\hline 1996 & 2.6 & 5.4 \\
\hline 1997 & 4.0 & 5.6 \\
\hline 1998 & 0.0 & 96.0 \\
\hline 1999 & 0.0 & 0.0 \\
\hline
\end{tabular}

Phillips et al. (2011) test regression), that is, there is a tendency to divert from the mean, each new observation with a faster pace. Such positive feedback is then displayed by positive changes in price levels and at the same time also positive changes (increases) in these positive changes. One may label the latter feature as positive acceleration. Hence, positive feedback may be observed when prices increase and at the same time these increases increase too. In Table 1, we present the fraction of stamps (out of the 500) for which, in particular years, price increases were positive (second column) and when changes in changes were positive (last column). Clearly, the years 1972 to 19781979 show many stamps with positive price changes and with positive acceleration. The joint occurrence of these two features is presented in Fig. 2. Figure 2 shows that in some years the fraction of stamps with positive feedback in prices can be as large as 0.6 or 0.7 . This occurs for the years 1976, 1977 and 1978, right before the price bubble 


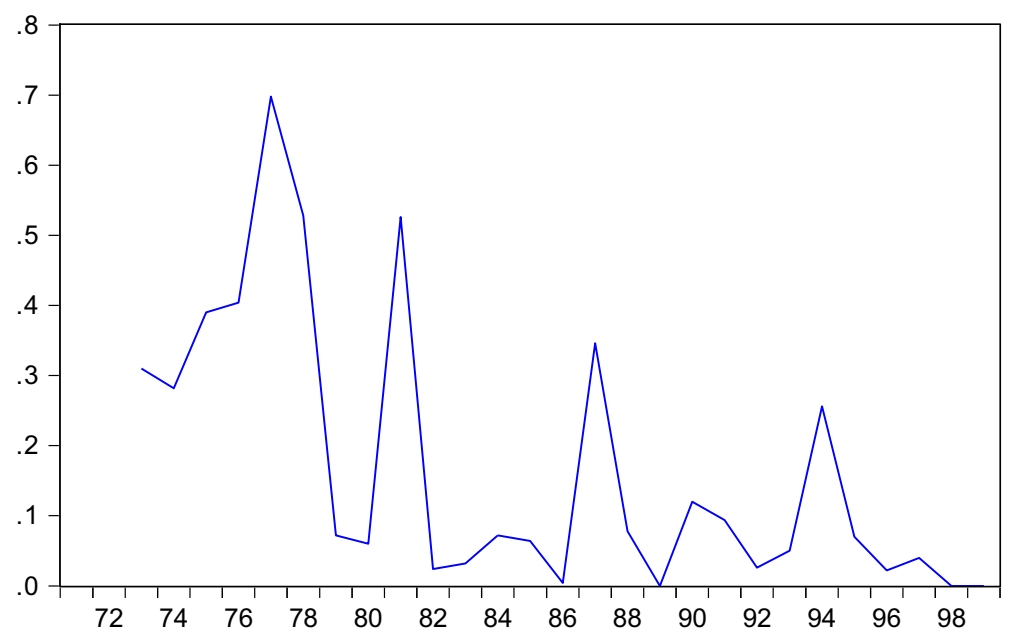

Fig. 2 Fraction of 500 stamps with a positive change in the index value and a positive acceleration (differences in changes are positive too), after correction for inflation, 1973-1999

appeared to burst. Hence, such positive feedback might be an indicator of a current bubble and perhaps even of an upcoming burst. Such a burst is clearly noted from a sharp drop in positive feedback in 1979 and 1980, which is the period that prices did not change much, on average.

To further on the notion of positive feedback, we report some key estimation results for binomial probit models for current positive feedback (the dependent variable has a value equal to 1 if positive feedback and equal to 0 for no positive feedback) on such feedback in the two years before. Table 2 shows the marked relevance of past positive feedback on future positive feedback in the bubble years 1975-1978, and a sharp drop in that relevance from 1979 onward. The likelihood ratio test statistics obtain very high values for the first part of the sample, and many of these values turn out to be insignificant in later years. Also, the parameters for past feedback are positive and significant in the bubble years, and a downturn can be witnessed in 1979 where Feedback $(t-1)$ is not relevant and Feedback $(t-2)$ obtains a negative and significant parameter estimate. Hence, it seems that amplifying positive feedback can be noticed from graphs and models, and hence, this should indicate that indeed bubblelike phenomena were occurring in these years. Below we will examine whether specific characteristics of the stamps have any mediating role.

A final impression of the heterogeneity across the development of stamp prices is shown in Fig. 3. The histogram concerns the number of years (from 1971) onward until the year with the peak price. Evidently, there seem to be at least two clusters of stamps with similar properties. There is a large group of stamps which peak after 8-10years and a group that peaks much later, around 23-24 years. It seems that the latter group is not to be associated with the price bubble, while members of the first group more likely are. Hence, Fig. 3 clearly shows the heterogeneity across the 500 stamps. There seem to be various clusters of stamps that show differences in the time between the start of the sample and the year of the peak price. It is quite likely therefore that more 
Table 2 Estimation results for binomial probit models (sample size is 500) to explain current positive feedback ( 1 and no positive feedback is 0 ) by positive feedback the year before and the year before that

\begin{tabular}{|c|c|c|c|}
\hline \multirow[t]{2}{*}{ Year } & \multicolumn{2}{|c|}{ Parameter estimates (and standard errors) } & \multirow[t]{2}{*}{ LR test } \\
\hline & Feedback $(t-1)$ & Feedback $(t-2)$ & \\
\hline 1975 & $0.438(0.127)$ & $0.341(0.124)$ & 18.13 \\
\hline 1976 & $0.307(0.118)$ & $0.566(0.128)$ & 30.16 \\
\hline 1977 & $0.646(0.132)$ & $0.723(0.135)$ & 62.87 \\
\hline 1978 & $0.635(0.130)$ & $0.384(0.120)$ & 44.29 \\
\hline 1979 & $0.090(0.176)$ & $-0.412(0.179)$ & 5.224 \\
\hline 1980 & $0.209(0.321)$ & $0.621(0.204)$ & 10.62 \\
\hline 1981 & $-0.177(0.238)$ & $0.568(0.230)$ & 6.783 \\
\hline 1982 & $-0.702(0.294)$ & NA & 6.840 \\
\hline 1983 & NA & $1.054(0.361)$ & 13.64 \\
\hline 1984 & $0.602(0.373)$ & NA & 2.394 \\
\hline 1985 & $-0.113(0.354)$ & $0.678(0.376)$ & 3.013 \\
\hline 1986 & NA & $0.940(0.534)$ & 2.661 \\
\hline 1987 & NA & $-0.195(0.243)$ & 0.654 \\
\hline 1988 & $0.168(0.170)$ & $1.493(0.893)$ & 3.471 \\
\hline 1989 & NA & NA & NA \\
\hline 1990 & NA & $1.315(0.217)$ & 36.22 \\
\hline 1991 & $0.143(0.227)$ & NA & 0.389 \\
\hline 1992 & $-0.092(0.430)$ & $0.544(0.284)$ & 3.379 \\
\hline 1993 & $0.273(0.522)$ & $0.717(0.248)$ & 7.816 \\
\hline 1994 & $-0.361(0.307)$ & $0.586(0.355)$ & 4.084 \\
\hline 1995 & $-0.265(0.214)$ & $-0.315(0.466)$ & 2.041 \\
\hline 1996 & $1.095(0.328)$ & $0.552(0.282)$ & 12.02 \\
\hline 1997 & NA & $0.187(0.358)$ & 0.258 \\
\hline 1998 & NA & NA & NA \\
\hline 1999 & NA & NA & NA \\
\hline
\end{tabular}

$L R$ value of the likelihood ratio test for the joint significance of these two variables. NA associates with a perfect fit or with only zero values for the regressor (boldface values are significant at the $5 \%$ level)

than one regression model might be needed to describe these data. For that matter and for later purposes, we estimate a mixture of normal distributions for these data, where we allow these distributions to have different variances. We experiment with two and three such distributions, but find that with three clusters one of these clusters contains not enough observations. Hence, we stick to two normal distributions. The first is a normal distribution with estimated mean of 9.953 (and estimated variance 2.876) and the second is a distribution with estimated mean 23.076 (and estimated variance of 1.590). A by-product of this exercise is that each observation corresponds with an estimated conditional probability that it belongs to the first and in part (or fully) to the second distribution (probabilities larger or smaller than 0.5). We will use these 


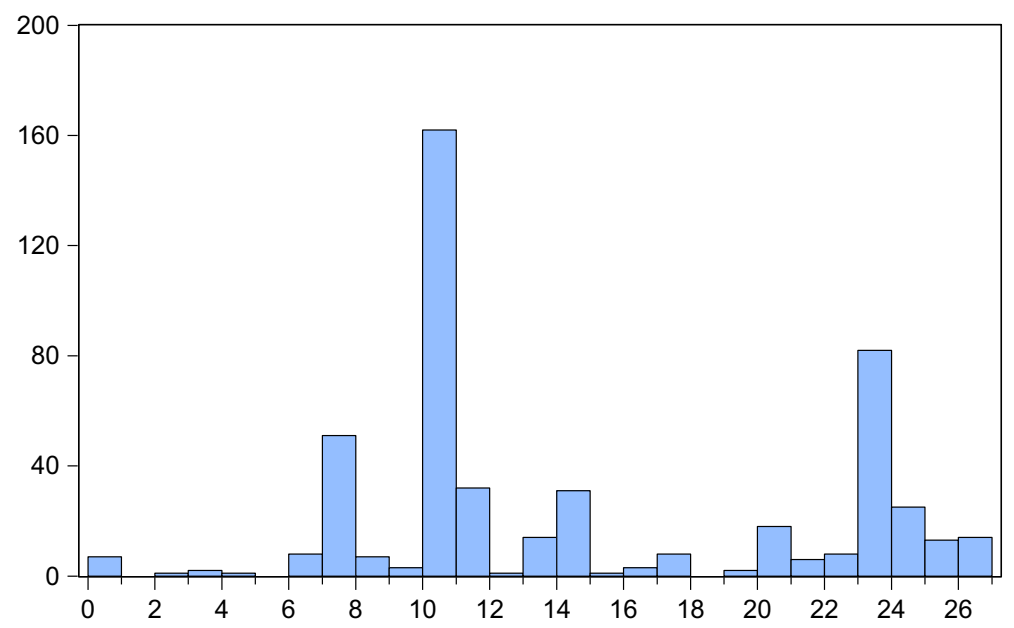

Fig. 3 Number of years from 1971 to the peak value of the price (amount on the vertical axis; number of years on the horizontal axis)

Table 3 Characteristics of 500 postage stamps

\begin{tabular}{lllll}
\hline Variable & Mean & Median & Minimum & Maximum \\
\hline Quantity issued $^{\mathrm{a}}$ & $14,054,509$ & $1,545,392$ & 205,700 & $9.36 \mathrm{E}+08$ \\
Quantity issued (in logs) $^{\mathrm{a}}$ & 14.847 & 14.251 & 12.234 & 20.657 \\
Amounts with series $^{\text {Additional price (in cents) }}$ & 6.528 & 5 & 1 & 24 \\
Children's benefit & 3.978 & 3 & 0 & 37.500 \\
Rank within series & 0.26 & 0 & 0 & 1 \\
\hline
\end{tabular}

A series of stamps has various values. Some series have one value; some have no $<24$. The rank in the series associates with a stamp's position within a series

${ }^{a}$ The variables have 467 observations

probabilities to classify the data when we turn to regression models for the natural logarithm of the years to the peak, see Table 5.

\section{Models}

In this section, we present the results of a few basic regression models, which aim to elicit various features of the data in times of a bubble and otherwise. We first present the properties of the 500 stamps, and then, we consider regression models to explain the peak price level and the time it took to obtain that level.

Table 3 presents a few characteristics of the 500 stamps. The minimum quantity issued is just over 200000, while the maximum number is over 900 million, and this range suggests an enormous diversity in the stamps. This can also be noted from the series lengths, which ranges from 1 to 24, and from the added price value (usually for 
Table 4 Characteristics of the prices of 500 postage stamps in the sample 1971-1999

\begin{tabular}{lcccc}
\hline Variable & Mean & Median & Minimum & Maximum \\
\hline Value in 1971 & 1.985 & 0.750 & 0.050 & 120.00 \\
Value in 1971 (in logs) & -0.190 & -0.288 & -2.996 & 4.787 \\
Value in 1990 & 3.996 & 3.333 & 0.417 & 20.00 \\
Corrected for inflation & 1.658 & 1.383 & 0.173 & 8.297 \\
Value in 1990 (in logs) & 1.125 & 1.204 & -0.875 & 2.996 \\
Corrected for inflation & 0.246 & 0.324 & -1.755 & 2.116 \\
Maximum price index & 5.775 & 5 & 1 & 35 \\
Corrected for inflation & 2.796 & 2.332 & 1 & 12.599 \\
Years to peak price index & 14.348 & 11 & 0 & 26 \\
Years from peak to lowest price & 4.86 & 5 & 0 & 19 \\
Years from 1971 to lowest price & 18.178 & 16 & 3 & 28 \\
\hline
\end{tabular}

a The variable has 297 observations

charity reasons), which ranges from 0 to 37.5 cents. In most years, the Dutch postal services issued so-called children's stamps, for which the additional fee was used for childcare charities. In sum, it seems that the data show much heterogeneity.

Table 4 presents various statistics on the price series over the years, and here the heterogeneity is illustrated even further. We will use the price level in the first sample year (1971) as one of the regressors later on, and from the first row of Table 4, we can see that there are substantial differences across price levels. In 1971, there were already stamps with price levels over 100 guilders, while the mean is just 1.985 guilders. To account for these skewed data, we will consider these 1971 prices after using the natural logarithmic transformation ("in logs"). To give an impression of after-bubble prices, we present the price levels of 1990, while other years in around that year give similar insights. After correction for inflation, we learn that price levels, on average, seem to have dropped from 1.985 to 1.658 , and it seems that in particular the high-priced stamps showed most significant price landings.

The maximum price index value is 5.775 , on average, with a median value of 5 years. The maximum price is 35 . Corrected for inflation, the maximum price level is 2.796 on average, which suggests a return of close to $280 \%$, at the peak of the bubble.

Finally, Table 4 shows in the bottom panel that the median number of years for prices to peak is 11 years. This suggests that during the period after the burst of the bubble, that is during 1979-1982, some stamps only by then reached top price levels, while for other stamps this peak occurred earlier and for many it occurred much later. The burst of the bubble seems to take only 4-5 years, as the average number of years from peak to the lowest price is 4.86 years.

\subsection{Modeling peak prices}

We first consider a standard regression model for the nominal price levels, and after that, we consider the same model for inflation-corrected price levels. Table 5 panel A 
Table 5 Estimation results for various regression models

\begin{tabular}{llll}
\hline Variable & \multicolumn{2}{l}{ Regression models } & \\
\cline { 2 - 4 } & $\mathrm{A}$ & $\mathrm{B}$ & $\mathrm{C}$ \\
\hline Intercept & $51.439(8.324)$ & $3.208(0.362)$ & $3.333(0.047)$ \\
Quantity issued (in logs) & $-0.087(0.023)$ & $-0.059(0.026)$ & $-0.012(0.003)$ \\
Year & $-0.025(0.004)$ & & $-0.041(0.012)$ \\
Children's benefit & $-0.153(0.058)$ & & $0.005(0.001)$ \\
Rank in series & & & $-0.012(0.004)$ \\
Size of series & $0.028(0.008)$ & & 0.192 \\
Additional price & & 0.034 & \\
Value in 1971 (in logs) & $0.074(0.024)$ & 0.257 & \\
Adjusted $R^{2}$ & & & \\
\hline
\end{tabular}

The full model contains all regressors, but the final model only includes $5 \%$ significant estimates (after stepwise deletion) (estimated White-corrected standard errors in parentheses)

A: Regression of nominal maximum price index value on various explanatory variables

B: Regression of the $\log$ of the number of years $(+1)$ in between 1971 and the year of the peak price on various explanatory variables, for the observations belonging to the left-hand side normal distribution in Fig. 3 (the relevant conditional probability $>0.5$ )

C: Regression of the log of the number of years $(+1)$ in between 1971 and the year of the peak price on various explanatory variables for the observations belonging to the right-hand side normal distribution in Fig. 3 (the relevant conditional probability $>0.5$ )

presents the estimation results to explain the nominal maximum price index value by an intercept, the quantity issued (after natural logarithmic transformation), the year the stamp was issued, a dummy variable if there was some added children's benefit, the rank in the series and the size of the series, a dummy variable if there was another additional surplus value, and the price value of 1971 (after taking natural logarithms). The table contains the results in case all insignificant parameters (at the $5 \%$ ) were set at 0 . The deletion of irrelevant variables is carried using a stepwise procedure, where each time the parameter with the largest $p$ value is set at 0 (and hence the associated variable is dismissed).

From panel A in Table 5, we learn that stamps, which were issued in larger quantities, which were issued more recently and which have a surplus for children's charity, have lower maximum price levels. At the same time, stamps in series with many items and higher initial price levels have higher maximum price levels. In other words, more valuable, older and scarce stamps reach higher maximum price levels. The fit of the model is close to 0.25 , which seems rather high for a cross section of data.

\subsection{Modeling time to and from the peak}

Panel B of Table 5 presents the estimation results, obtained in a similar way as above, for the regression model to explain the log of the number of years ( 1 added to avoid zeroes) in between 1971 and the year of the peak price. This table only documents the estimation results for the observations which are associated with the left-hand distrib- 
Table 6 Regression of the log of the number of years in between the year of the peak price and the year of the trough on various explanatory variables (estimated White-corrected standard errors in parentheses)

\begin{tabular}{lll}
\hline Variable & Years +1 & Tobit model \\
\hline Intercept & $-47.50(14.01)$ & $-84.07(23.54)$ \\
Quantity issued (in logs) & $-0.119(0.040)$ & $-0.232(0.072)$ \\
Year & $0.026(0.007)$ & $0.045(0.012)$ \\
Children's benefit & $-0.303(0.100)$ & $-0.473(0.174)$ \\
Rank in series & $0.065(0.032)$ & $0.139(0.048)$ \\
Size of series & $-0.046(0.017)$ & $-0.123(0.035)$ \\
Additional price & $3.977(1.014)$ & $4.497(1.982)$ \\
Value in 1971 (in logs) & $0.146(0.053)$ & $0.267(0.094)$ \\
Adjusted $R^{2}$ & 0.223 & $1.470(0.070)$ \\
Scale parameter & & \\
\hline
\end{tabular}

ution in Fig. 3, which are 305 observations. Interestingly enough, for this cluster only the quantity issued is significant. Hence, stamps that reach their price peak faster are the scarcer stamps, as quantity obtains a negative and significant parameter estimate.

Panel $\mathrm{C}$ of Table 5 presents the results for the right-hand distribution of Fig. 3 (162 observations), and here, we see that again quantity is important, though with a smaller-sized parameter (than the one in panel B). Interestingly, the initial price level of 1971 obtains a negative parameter, implying that initially higher-valued stamps (in that cluster) peak earlier.

Table 6 reports on the estimation results for two models for the number of years from the peak price to the lowest price. In other words, this is the time that it takes for the bubble to burst. A shorter time period means that price levels drop more rapidly. As the dependent variable can take zero values, we report on a regression model for years +1 and a censored regression model in the right-hand column of Table 6 . Clearly, the parameters in both models obtain the same estimated signs and are also approximately similar in size. Zooming in on some of the key variables, we learn from Table 6 that higher-valued, scarce and more recently issued stamps have a longer time in between peak and trough, while initially lower-valued and abundantly issued stamps witness rapid price drops after the bubble bursts. This is an indication that the latter type of stamps joins in the price bubble, but they are also the first to show sharp price landings. The rare and higher-valued stamps seem to suffer less from the price bubble.

In Table 7, we present estimation results of binomial probit models to explain positive feedback (like in Table 2), where we now include only one lag of feedback, and we also include all the regressors as in the previous tables. To save space, we only report the estimation results for the variables "quantity issued" and "value in 1971 " as these two variables appear to be most relevant. In the last two columns, we present the hit rate and the Likelihood Ratio (LR) test for the joint significance of all variables. To start with these last two columns, we learn that the probit models have quite an accurate fit, while the LR test values are highest in the bubble years. During the bubble years 1975-1977, we also see that quantity and initial value obtain 
Table 7 Selective results from binomial probit models to explain of positive feedback (positive change and change in the change is also positive): parameter estimates for quantity issued (in log) and value in 1971 (in $\log$ ), the estimated hit rate and LR test statistic for the joint significance of all variables as in Table 2 plus 1-year lagged feedback (boldface parameters are significant at the $5 \%$ level)

\begin{tabular}{|c|c|c|c|c|}
\hline Year & Quantity issued & Value in 1971 & Hit rate $(\%)$ & LR test \\
\hline 1974 & $-0.049(0.063)$ & $0.230(0.074)$ & 68.52 & 71.08 \\
\hline 1975 & $-0.174(0.056)$ & $0.162(0.078)$ & 72.59 & 112.8 \\
\hline 1976 & $-0.110(0.062)$ & $0.362(0.082)$ & 70.02 & 113.1 \\
\hline 1977 & $-0.237(0.061)$ & $0.419(0.089)$ & 73.88 & 136.5 \\
\hline 1978 & $-0.243(0.070)$ & $0.004(0.080)$ & 69.59 & 118.6 \\
\hline 1979 & $-0.003(0.161)$ & $-0.043(0.178)$ & 73.88 & 63.60 \\
\hline 1980 & $-0.504(0.164)$ & $\mathbf{- 0 . 4 2 2}(0.179)$ & 67.67 & 32.57 \\
\hline 1981 & $0.072(0.054)$ & $0.325(0.072)$ & 62.31 & 40.30 \\
\hline 1982 & $-0.286(0.276)$ & $-0.680(0.357)$ & 76.81 & 23.80 \\
\hline 1983 & $0.314(0.104)$ & $0.482(0.108)$ & 73.23 & 24.32 \\
\hline 1984 & $0.168(0.079)$ & $0.405(0.100)$ & 70.02 & 45.96 \\
\hline
\end{tabular}

Fig. 4 Natural logarithm of sales (in units) versus the years of issue

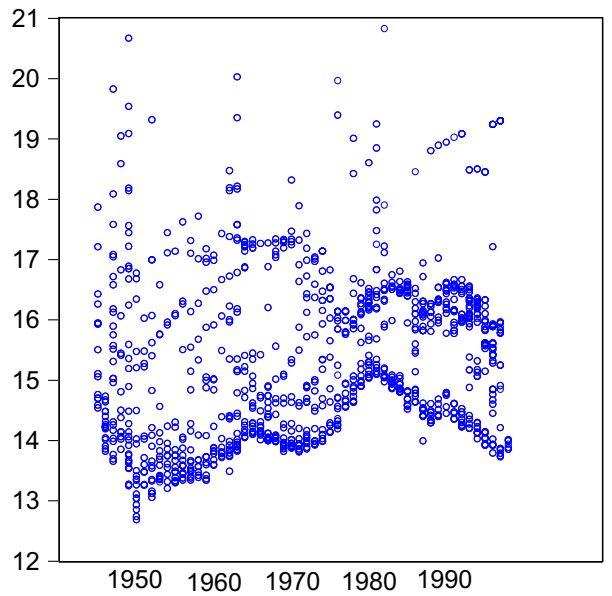

significant parameter estimates, suggesting the scarce and high-valued stamps also drive the positive feedback. In 1978 the quantity is still relevant, but in the year of the price burst the two variables turn out to be irrelevant.

Finally, as LeRoy (2004) indicates, for stamp prices to show a bubble, there must be a specific reason why such a bubble could occur. One such reason may be that the collection of stamps became very popular in the relevant years and hence that demand for stamps suddenly increased, see footnote 1. In Fig. 4, we depict the log of the numbers of issued new stamps since 1945, and it is clear that there is an upward trend from the mid-1970s to the beginning of the eighties. The Dutch postal services recognized the increasing popularity of collecting stamps and started to sell in larger quantities. They also issued special themes and books, and again, our anecdotal information is 
that many stamp collectors could not keep up the pace, also in terms of money, and after around 1985 stamp collecting became much less popular.

\section{Conclusions and implications}

The empirical analysis in this paper leads to various conclusions. First, in studying price bubbles, it may be insightful to examine the price patterns of all components and not just a single index. Specific properties of the 500 stamps seemed informative for the bubble period and also for the period right after the burst of the bubble. Second, we documented that scarce and higher-priced collectible stamps reach higher peak levels at the top of the bubble, whereas scarce stamps also reach this peak level faster, while the very same types of stamps witness a slower pace in times when price levels drop to trough values. For investment purposes, these stamps seem to be the best buy, although also these stamps show tremendous drops in value once the bubble is over.

At a more general level, we also obtained insights on the data properties at the time of the price bubbles. We saw that during the bubble the number of stamps with such positive feedback is over $50 \%$ or even higher, and this suggests that an analysis such as ours can be very informative about the current state of affairs. We also noted that properties of the stamps, like scarcity and initial price levels, mediate the positive feedback, that is, these types of stamps substantially contribute to the price bubble. Other stamps are taken along in the upswing of prices, but once the bubble bursts, these stamps quickly lose their value.

An important implication of our study is that it pays off to look at the assets at a more detailed level, when analyzing price level conditions. Of course, a composite index can be useful too, but we showed that individual characteristics of the assets had a mediating and signaling role. This insight might be useful when analyzing bubbles in other markets. Typically, one analyzes the top-level prices of artists' works, but our results suggest that analyzing all works of these artists can be beneficial. The same holds true for the dot.com bubble, where perhaps some companies did not suffer as much as others did due to some specific features of these companies. Similarly, not all stocks may peak at the same time, and the burst of a stock market bubble may be different for different stocks.

Open Access This article is distributed under the terms of the Creative Commons Attribution 4.0 International License (http://creativecommons.org/licenses/by/4.0/), which permits unrestricted use, distribution, and reproduction in any medium, provided you give appropriate credit to the original author(s) and the source, provide a link to the Creative Commons license, and indicate if changes were made.

\section{References}

Cardell NS, Kling JL, Petry G (1995) Stamp returns and economic factors. South Econ J 62:411-427

Dimson E, Spaenjers Ch (2011) Ex post: the investment performance of collectible stamps. J Financ Econ 100:443-458

Franses PH (2015) A simple test for a bubble based on growth and acceleration. Comput Stat Data Anal (in print)

Froot KA, Obstfeld M (1991) Intrinsic bubbles: the case of stock prices. Am Econ Rev 81:1189-1214 
Galbraith JK (1993) A short history of financial euphoria. Viking, New York

Garber PM (1990) Famous first bubbles. J Econ Perspect 4:35-54

Homm U, Breitung J (2012) Testing for speculative bubbles in stock markets: a comparison of alternative methods. J Financ Econom 10:198-231

LeRoy SF (2004) Rational exuberance. J Econ Lit 42:783-804

Pesando JE (1993) The market for modern prints. Am Econ Rev 83:1075-1089

Phillips PCB, Wu Y, Yu J (2011) Explosive behaviour in the 1990s Nasdaq: when did exuberance escalate asset values? Int Econ Rev 52:201-226

Smith VL, Suchanek GL, Williams AW (1988) Bubbles, crashes, and endogenous expectations in experimental spot asset markets. Econometrica 56:1119-1151

Veld Ch, Veld-Merkoulova YV (2007) Portfolio diversification benefits of investing in stamps. J Altern Invest 10:56-61

West KD (1987) A specification test for speculative bubbles. Q J Econ 102:553-580 